\title{
Perspectives of Canadian Teacher Candidates on Inclusion of Children with Developmental Disabilities: A Mixed-Methods Study
}

\author{
Nancy Hutchinson, Patricia Minnes \\ Queen's University \\ Julie Burbidge \\ University of Alberta Hospital \\ Jenn Dods \\ Queen's University \\ Angela Pyle \\ OISE, University of Toronto \\ CJ Dalton \\ Queen's University
}

\begin{abstract}
This mixed-methods study reports on the perspectives of 208 teacher candidates on teaching children with developmental disabilities and delays (DD) in inclusive classrooms from Kindergarten to Grade 6. The questionnaire included items on demographics, experience, knowledge, and feelings of competence, advocacy, and sense of efficacy. Open-ended questions addressed challenges and successes experienced when including children with DD. Findings suggest that qualitative items elicited more positive responses than traditional questionnaire items and elicited more nuanced and sophisticated understanding of the challenges and successes associated with social inclusion. In the qualitative data, respondents showed understanding of dilemmas associated with inclusive education. Feelings of competence about teaching children with DD and about collaborating with colleagues predicted general sense of efficacy scores; those with experience advocating for individuals with disabilities reported greater knowledge, experience, and confidence related to teaching students with DD. Knowledge, experience, and confidence were highly correlated. Implications for teacher education are discussed.
\end{abstract}


Every province and territory in Canada has mandated inclusive education for children and adolescents with disabilities (Hutchinson, 2014). Thus teacher education programs currently include courses on topics like inclusion and differentiated instruction, and teacher candidates complete practica in schools striving to meet these mandates for inclusive education. What are the perspectives of teacher candidates while they are experiencing these courses and practica? Previous studies have reported that pre-service teacher candidates hold generally positive views of inclusion, similar to the views of inservice teachers (e.g., Avramidis, Bayliss, \& Burden, 2000; Stanovich, 1999; Swain, Nordess, \& Leader-Janssen, 2012). However, questionnaire research has tended to pose implicitly negative questions (Robinson, Shaver, \& Wrightsman, 1991; Tourangeau, Rips, \& Rasinski, 2000), in this case about the concerns and stresses candidates associate with teaching children with disabilities. For example, Forlin, Loreman, Sharma, and Earle (2009) included questions such as, which is more challenging, including children with emotional difficulties or with intellectual disabilities? Studies have also focused on candidates' concerns over issues like "increase in workload" and "inadequate resources and special education staff" (Subban \& Sharma, 2005), and there have been few mixedmethods studies (cf. Swain et al.). One of the few studies of teachers' perspectives, specifically on the inclusion of children with developmental disabilities (DD), used the SACIE-R (Sentiments, Attitudes, and Concerns about Inclusive Education-Revised) by Forlin, Earle, Loreman, and Sharma (2011). Montgomery and Mirenda (2014) reported that higher self-efficacy for collaboration was the only predictor associated with more positive sentiments and with fewer concerns about inclusive education for practising teachers. Given that the parents of children with DD are among the strongest proponents of social inclusion (Clegg, Murphy, Almach, \& Harvey, 2008), there is a need for further research on the perspectives of practising teachers and of teacher candidates on the inclusion of children with DD. Developmental disabilities and delays refer to delayed milestones, physical disabilities, sensory impairments, and intellectual disabilities including autism spectrum disorders.

\section{Purpose}

The purpose of the current study was to report the perspectives of Canadian teacher candidates, who were preparing to teach in general education classrooms, on their experiences and their perceptions of their ability to meet the needs of students with DD in inclusive classrooms. We set out to use an appreciative approach (Preskill \& Catsambas, 2006) and to report both qualitative and quantitative data, thus enabling teacher candidates to describe their perceptions of successes as well as of challenges. In reporting the quantitative data, we focused on self-reports of competence and self-efficacy, as well as experience, knowledge, experience advocating, and desire for further education. The qualitative data provided clear examples of the teacher candidates' robust understanding of inclusion, collaboration, and the dilemmas surrounding both that must be addressed in teacher education. The resulting paper adds to the limited data on Canadian teacher candidates' perspectives on inclusion of children with DD and discusses the implications for research and for teacher education programs. 


\section{Theoretical Framework and Related Literature}

Recent research with teachers and teacher candidates has demonstrated that their beliefs and attitudes about disabilities and about their responsibilities for students with disabilities are closely related to their effectiveness in inclusive classrooms (Jordan, Glenn, \& McGhie-Richmond, 2010; Sokal \& Sharma, 2014). However, findings of research on the relationship of teacher candidates' characteristics to their beliefs and attitudes about inclusion have been inconsistent. Females tend to be more positive than males, while age, grade level taught, subject taught, and nature of pre-service education about students with disabilities have not been consistently related (Avramidis et al., 2000; Symeonidou \& Phtiaka, 2009). General self-efficacy and feelings of confidence about teaching students with disabilities have been related to beliefs and attitudes about inclusion (Ajuwon et al., 2012; Brady \& Woolfson, 2008; Sari, Celikoz, \& Secer, 2009), but what is less clear is how efficacious teacher candidates feel, specifically, about teaching students with DD in inclusive classrooms. An early study showed that $96 \%$ of a sample of pre-service teachers felt unprepared to teach students with Down syndrome in inclusive settings (Wishart \& Manning, 1996). Recent studies suggest that many aspects of pre-service teachers' experiences may merit investigation. Because collaboration is frequently recommended as a strategy for meeting students' needs in inclusive classrooms (Arthaud, Aram, Breck, Doelling, \& Bushrow, 2007; Villeneuve \& Hutchinson, 2012) - and was found relevant in a recent study of practising teachers (Montgomery \& Mirenda, 2014) - teacher candidates' experience with, and confidence in, their ability to engage in collaboration may contribute to their attitudes and beliefs about inclusion. Also, first-hand experience with individuals with disabilities has been found to contribute to attitudes about inclusion (e.g., Ajuwon et al., 2012; Brady \& Woolfson, 2008). Thus teacher candidates' experiences advocating for those with disabilities may also be related to their beliefs and attitudes about inclusion. Stanovich's (1999) focus group research with experienced teachers suggested that when asked about positive experiences with inclusion, educators provided data about their successes as well as their challenges in inclusive classrooms. Swain et al. (2012) reported that in openended responses on a survey, pre-service candidates' data yielded positive as well as negative themes about inclusion. This led us to include opportunities for participants to provide open-ended responses about successes as well as challenges and to include questionnaire items that were not implicitly negative in their wording (Robinson et al., 1991; Tourangeau et al., 2000). We anticipated that this approach might elicit positive experiences and perspectives from teacher candidates, indicative of academic optimism about inclusion (Stansberry Beard, Hoy, \& Woolfolk Hoy, 2010).

\section{Method}

\section{Participants}

The survey was completed by 208 candidates in an eight-month post-degree licensure program who were preparing to teach Kindergarten to Grade 6 in general education classrooms. The program was at a university Faculty of Education in the province of Ontario, Canada. The institution's vision for teacher candidates included "the 
development of a socially inclusive pedagogy" and "a disposition to work in collaboration with other members of the profession and all those involved in the education and development of all learners." Prior to participating in this study, all candidates had completed an 18-hour course focused on learning "about adapting instruction for exceptional learners and about equity issues." Participants had completed four months of the eight-month program and had participated in eight weeks of practicum in classrooms. There was a substantially higher proportion of women respondents $(88 \%)$ than men $(12 \%)$, reflecting enrolment data for the program $(83 \%$ women, $17 \%$ men; personal communication, March 2011). Participants ranged in age from 22 to 48 years $(M=24.89, S D=4.41)$.

\section{Measures}

An instrument was developed incorporating items from the McGill Inclusive Education Questionnaire (MIEQ; Daniel \& Cornish, 2006) on training, experience, knowledge, and resources. The MIEQ was developed following (a) an extensive review of research on teacher beliefs about and perceptions of inclusion and (b) interviews with teachers and special needs consultants across Quebec. After review by educational researchers and teachers, the questionnaire was piloted with 20 experienced teachers. Revisions were made after each of these reviews (Daniel, 2011). New items, specific to the inclusion of students with DD, that emphasized successes as well as challenges, were developed for the current study. Many questions directed respondents to answer based on their most recent practicum experience in a school. We also included the 13-item Teachers' Sense of Efficacy Scale Short Form (Tschannen-Moran \& Woolfolk Hoy, 2001).

Training, experience, knowledge, competence, and collaboration. Participants answered two questions about their training in DD. For each academic course and each workshop, they selected the included topics from a list of 11 (e.g., social inclusion, Down syndrome, hearing or visual difficulty). An other option was provided for any question where it made sense, including these two.

Experience working with people with DD was measured using two questions with 4point scales. The first question was about their experience working with children, adolescents, and adults; and the second was about the types of disabilities of children they had recently worked with in practicum (from a list of 10 including Down syndrome and hearing or visual difficulty). The 4-point scale ranged from 1 (very limited) to 4 (extensive).

Knowledge of DD was measured using a single item that asked participants to rate their knowledge of working with students with the same 10 types of DD on the 4-point scale. Two questions assessed participants' feelings of competence using a 4-point scale: how competent they felt collaborating with educators, health providers, and other professionals; and how competent they felt meeting the needs of children with DD.

Resources. Participants identified which of four types of resources they had access to during practica (i.e., web-based material, written material, information from workshops or seminars, and information from colleagues), and which of these resources they had found most helpful. They identified any of seven types of specialized curriculum or classroom resources that were available in their practicum schools (e.g., specialized 
computer software, manipulatives), and whether there were resource teachers or consultants assigned to these schools. Candidates reported whether they had participated in a resource team meeting, who was present at this meeting, and whether their host teacher had referred to the individual education plans (IEP) or behavioural support plans of students in their classes.

Desire for further education. Three items, using 4-point scales, asked about participants' desire for further knowledge and training: (a) how an increase in knowledge about different DD would impact their effectiveness in working with children with DD in the inclusive classroom, (b) how an increase in knowledge about collaboration would impact their effectiveness in working with children in the inclusive classroom, and (c) if they would like more training in eight areas (e.g., classroom management, language skills) related to teaching students with DD.

Successes and challenges. Participants were given a list of four potential successes (e.g., more collaboration and partnership with parents) and eight potential challenges (e.g., difficulty managing behaviour). They were asked to identify any that their school was experiencing in including students with DD in the classroom. An additional question listed seven potential stressors (e.g., working with a student with a poor attention span) and asked participants to identify any that they had experienced while working in an inclusive setting.

Advocacy. An adapted version of the Parent Advocacy Scale (Nachshen, Anderson, \& Jamieson, 2001) measured actions taken in the past year to advocate for individuals with DD, asking respondents the number of times they had participated in five advocacy activities (i.e., phone calls, office visits or meetings, letters or mass mailings, media contacts, and "other" activities), whether the activity was conducted to meet the needs of a child in their care or others with DD, and whether the activity made a difference. They were also asked whether they belonged to any organizations or groups supporting children with DD.

Self-efficacy. The Teachers' Sense of Efficacy Scale Short Form (Tschannen-Moran \& Woolfolk Hoy, 2001) is a 13-item measure of the respondents' confidence in meeting the needs of all students including students with disabilities (e.g., How well can you implement an inclusive learning environment?). Respondents were asked to indicate the degree of confidence about each item using a 9-point scale ranging from 1 (not at all) to 9 (a great deal). Cronbach's alpha for this study was .91.

Qualitative data. Two open-ended questions provided qualitative data, one on challenges and one on successes. Participants were asked to write about an example of a time when they felt successful and a time when they faced challenges in meeting the needs of a child with DD. For both questions, participants were also asked to write about how their actions impacted the child's social inclusion. 


\section{Procedures}

The study received ethical clearance in the institution where the research was conducted. A panel of experts reviewed the instrument to establish content validity. Teacher candidates voluntarily completed the survey at a supervised lecture, and those who chose to were free to leave or to submit the instrument to the researcher without completing it. The 208 who completed the survey represented $95 \%$ of the students in attendance at the supervised lectures when the surveys were distributed and $59 \%$ of the 350 enrolled in the program. Completion typically required 20 minutes.

\section{Results}

The results are presented in two sections, the quantitative data followed by the qualitative data. The six sections in the quantitative data report on: self-perceptions of knowledge, experience, and competence; resources in schools; desire for further education; advocacy; self-efficacy; and perceptions of successes, challenges, and stressors. In the qualitative data, the three themes in the open-ended responses about successes are reported first (differentiating teaching, increasing participation, and working with other adults), followed by the four themes in the responses about challenges (disruptive behaviour, differentiating teaching, differences in adult perspectives, and being a teacher candidate).

\section{Quantitative Data}

Perceived knowledge, experience, and sense of competence working with children with DD. Social inclusion was the most common topic on which participants had received training in academic courses and workshops (Table 1). Teacher candidates reported that autism was the most commonly studied type of disability in courses and workshops, and this was the DD with which they reported having the most experience during practicum and the greatest knowledge. Developmental delays were rated second highest in the same four areas. The third most frequently reported specific disability varied across the categories, with hearing and/or visual difficulty being reported most frequently for knowledge and academic courses, and non-specific intellectual disabilities for seminars or workshops and experience. The data suggest that the candidates were least familiar with Tourette syndrome, epilepsy, and Fragile X syndrome, with these three disabilities rated lowest for academic courses, seminars and workshops, experience, and knowledge.

The majority of respondents (68.6\%) reported that they had moderate to extensive experience working with children with special needs, whereas far fewer participants reported moderate to extensive experience working with adolescents $(34.1 \%)$ or adults (16.8\%) with special needs. Respondents were most likely to have had recent practicum experience with children with autism spectrum disorder, developmental delay, non-specific intellectual disability, and hearing and/or visual difficulty; and they rated their knowledge of these four disability types the highest (Table 1). In contrast, respondents were least likely to have had experience with children with epilepsy, Fragile X syndrome, and Tourette syndrome; and they rated their knowledge of these three disability types the lowest. 


\section{Table 1}

Participants' Courses, Training, Practicum Experience, and Knowledge Related to Developmental Disabilities

\begin{tabular}{|c|c|c|c|c|c|c|c|}
\hline \multirow[t]{2}{*}{ Topic } & \multicolumn{2}{|c|}{$\begin{array}{l}\text { Courses in } \\
\text { Academic } \\
\text { Program }\end{array}$} & \multicolumn{2}{|c|}{$\begin{array}{l}\text { Training } \\
\text { Seminars/ } \\
\text { Workshops }\end{array}$} & \multicolumn{2}{|c|}{$\begin{array}{l}\text { Recent } \\
\text { Practicum } \\
\text { Experience }\end{array}$} & \multirow[t]{2}{*}{$\begin{array}{l}\text { Current } \\
\text { Knowledge }\end{array}$} \\
\hline & $N$ & (\%) & & (\%) & & $(\%)$ & \\
\hline $\begin{array}{l}\text { Social inclusion of children } \\
\text { with developmental delays or } \\
\text { disabilities }\end{array}$ & 179 & $(86.1)$ & 83 & $(39.9)$ & & & \\
\hline Autism spectrum disorder & 166 & $(79.8)$ & 60 & $(28.8)$ & 146 & $(70.2)$ & $2.57(0.72)$ \\
\hline Developmental delay & 131 & $(63.0)$ & 35 & $(16.8)$ & 105 & $(50.5)$ & $2.41(0.82)$ \\
\hline $\begin{array}{l}\text { Hearing and/or visual } \\
\text { difficulty }\end{array}$ & 123 & $(59.1)$ & 26 & $(12.5)$ & 81 & $(38.9)$ & $2.22(0.91)$ \\
\hline Fetal alcohol syndrome & 120 & $(57.7)$ & 16 & $(7.7)$ & 40 & $(19.2)$ & $1.98(0.82)$ \\
\hline $\begin{array}{l}\text { Non-specific intellectual } \\
\text { disability }\end{array}$ & 109 & $(52.4)$ & 30 & $(14.4)$ & 103 & $(49.5)$ & $2.20(0.78)$ \\
\hline Down syndrome & 106 & $(51.0)$ & 16 & (7.7) & 34 & $(16.3)$ & $2.09(0.82)$ \\
\hline Physical disabilities & 104 & $(50.0)$ & 29 & $(13.9)$ & 57 & $(27.4)$ & $2.06(0.88)$ \\
\hline Tourette syndrome & 74 & $(35.6)$ & 7 & (3.4) & 6 & $(2.9)$ & $1.63(0.76)$ \\
\hline Epilepsy & 42 & $(20.2)$ & 6 & $(2.9)$ & 18 & $(8.7)$ & $1.88(0.86)$ \\
\hline Fragile $X$ syndrome & 47 & $(22.6)$ & 3 & $(1.4)$ & 7 & $(3.4)$ & $1.31(0.54)$ \\
\hline
\end{tabular}

Note. Categories are not mutually exclusive.

A McNemar test was conducted to determine whether the proportion of teacher candidates who reported feeling competent (combining moderately competent and very competent) to meet the needs of children with DD was different from the proportion of teacher candidates who reported feeling competent (combining moderately competent and very competent) to collaborate with other professionals. The results were significant, $\chi^{2}(1, N=205)=16.30, p<.001$, indicating that the proportion of teacher candidates who reported feeling competent to collaborate with professionals $(56.1 \%)$ was significantly higher than the proportion of candidates who reported feeling competent to meet the needs of children with DD (37.6\%).

All Pearson correlations among experience working with children with special needs, adolescents with special needs, and adults with special needs, total feelings of competence, and mean knowledge score across all disability types were significant, $p<$ .01 (Table 2). This indicates that greater amounts of general experience with individuals with special needs, greater knowledge of DD, and higher feelings of competence were all related to one another. 
Table 2

Pearson Correlations for Experience, Feelings of Competence, and Knowledge

\begin{tabular}{lllll}
\hline \multicolumn{1}{c}{ Measure } & $\mathbf{1}$ & $\mathbf{2}$ & $\mathbf{3}$ & $\mathbf{4}$ \\
\hline 1. Experience with children with special needs & -- & & & \\
2. Experience with adolescents with special needs & $.611^{*}$ & -- & & \\
3. Experience with adults with special needs & $.369^{*}$ & $.539^{*}$ & -- & \\
4. Total feelings of competence & $.286^{*}$ & $.231^{*}$ & $.233^{*}$ & -- \\
5. Mean knowledge scores across disabilities & $.505^{*}$ & $.454^{*}$ & $.307^{*}$ & $.355^{*}$ \\
\hline
\end{tabular}

${ }^{*} p<.01$.

Resources candidates experienced in their schools. Colleagues and web-based materials were the resources that teacher candidates reported using most, with colleagues being the most helpful resource (Table 3). The most common specialized curriculum or classroom resource to which respondents reported having access was manipulatives (77.0\%). Reported access to other resources included: specialized computer software (58.7\%), adaptive equipment (41.8\%), specialized visual materials $(36.5 \%)$, and specialized books (36.1\%). Eleven respondents $(5.3 \%)$ reported no specialized curriculum or classroom resources in their practicum schools, and nine specified examples of other resources, including sensory resources (e.g., for hearing), a specialized classroom in the school, and a specialized computer.

Table 3

Participants' Experiences of Resources in Practicum Schools

\begin{tabular}{|c|c|c|}
\hline \multirow{3}{*}{$\begin{array}{l}\text { Resources } \\
\text { Information obtained from colleagues }\end{array}$} & \multicolumn{2}{|c|}{$N(\%)$} \\
\hline & $\begin{array}{l}\text { Used When in } \\
\text { School }\end{array}$ & $\begin{array}{l}\text { Was Most Usefu } \\
\text { When in School }\end{array}$ \\
\hline & $189(90.9)$ & $154(74.4)$ \\
\hline Web-based material & $185(88.9)$ & $56 \quad(27.1)$ \\
\hline Written material (books, journal articles, etc.) & $132(63.5)$ & $42(20.3)$ \\
\hline $\begin{array}{l}\text { Information obtained from workshops, } \\
\text { training sessions }\end{array}$ & $75(36.1)$ & $38 \quad(18.4)$ \\
\hline Other & $30(14.4)$ & $14 \quad(6.8)$ \\
\hline
\end{tabular}

Note. Categories are not mutually exclusive.

Most teacher candidates (87.4\%) reported that resource teachers had been assigned to the schools in which they had completed their practica. A third of teacher candidates (36.5\%) did not know how often these resource teachers met with staff, with the remainder reporting that meetings took place daily $(27.1 \%)$, weekly $(21.0 \%)$, or monthly $(14.3 \%)$. Only about one quarter of the teacher candidate respondents $(24.4 \%)$ had attended a resource team meeting. The people whom respondents identified as most 
likely to attend resource team meetings were the resource teacher (identified by $92.2 \%$ ), the principal (identified by $56.9 \%$ ), and the parent (identified by $58.8 \%$ ). Other attendees who were identified by respondents included vice-principals $(23.5 \%)$, speech and language pathologists $(23.5 \%)$, psychologists $(17.6 \%)$, occupational therapists $(13.7 \%)$, school board consultants $(9.8 \%)$, childcare workers $(9.8 \%)$, and physiotherapists $(3.9 \%)$. Close to half of respondents $(41.2 \%)$ did not know how often the resource team met. The majority of candidates (85.8\%) reported that their host teachers had used or described the individual education plan (IEP) or behavioural support plan for students they taught.

Desire for further education to teach children with DD. Participants reported increasing their knowledge about DD would have a moderate $(25.1 \%)$ or significant (72.5\%) impact on their effectiveness in working with children in an inclusive classroom. Similarly, most participants indicated that an increase in knowledge about collaboration would also have a moderate $(31.4 \%)$ or significant $(68.1 \%)$ impact on their effectiveness working with children in an inclusive classroom.

Teacher candidates reported the need for further training and education in numerous areas: behaviour interventions $(89.9 \%)$, academic modifications $(85.6 \%)$, classroom management $(82.7 \%)$, social skills $(78.4 \%)$, language skills $(62.0 \%)$, motor skills $(53.8 \%)$, memory $(53.8 \%)$, and sensory $(51.9 \%)$. Sixteen teacher candidates also reported they would like more training and education in other areas: making accommodations in teaching and assessment $(n=7)$, social interactions including communicating with families and creating an accepting environment $(n=3)$. Six did not specify the other area.

Advocacy. Few candidates (50 of 203) reported advocacy experience. A small number $(14.5 \%)$ reported that they belonged to an organization or group that supported children with DD, $10.3 \%$ had attended meetings for advocacy, and $7.3 \%$ had taken other advocacy actions. Only one teacher candidate responded with the view that the action taken had not made a difference, whereas the other candidates indicated that the action had made a difference or they were unsure whether it had made a difference. Attending meetings and making phone calls were the most frequently reported types of advocacy to meet the needs of a child in the teacher candidate's class.

Independent samples $t$-tests were conducted to compare the 50 teacher candidates who reported participating in advocacy or being members of an advocacy organization to the 153 candidates who did not participate in either. The descriptive statistics and the independent samples $t$-test data are reported in Table 4. Those with advocacy experience reported significantly greater overall experience with children, adolescents, and adults with special needs as well as significantly higher mean knowledge scores across all disability types. Those with advocacy experience also reported that they had attended significantly more workshops and seminars on DD, and their total reported feelings of competence (for meeting the needs of students with DD and for collaborating) were significantly higher than those reported by candidates without advocacy experience. There were no significant differences between advocates and non-advocates on six variables: age; total number of disability types worked with in last practicum; total number of DD topics covered in courses; total number of perceived challenges faced by schools; total number of stressors faced by candidates; and mean score on teacher self-efficacy scale. 
Table 4

Results of Independent Samples t-tests

\begin{tabular}{|c|c|c|c|c|c|}
\hline Measure & Respondents & $M(S D)$ & $t$ & $d f$ & $p$-value \\
\hline Age & $\begin{array}{l}\text { Non-advocates } \\
\text { Advocates }\end{array}$ & $\begin{array}{l}24.73(4.41) \\
24.64(3.38)\end{array}$ & 0.125 & 201 & .900 \\
\hline $\begin{array}{l}\text { Mean experience with } \\
\text { DD (all ages) }\end{array}$ & $\begin{array}{l}\text { Non-advocates } \\
\text { Advocates }\end{array}$ & $\begin{array}{l}2.14(0.70) \\
2.45(0.78)\end{array}$ & 2.65 & 201 & .009 \\
\hline $\begin{array}{l}\text { Total types of DD in last } \\
\text { practicum }\end{array}$ & $\begin{array}{l}\text { Non-advocates } \\
\text { Advocates }\end{array}$ & $\begin{array}{l}3.03(1.45) \\
3.08(1.45)\end{array}$ & 0.23 & 201 & .82 \\
\hline $\begin{array}{l}\text { Mean knowledge score } \\
\text { across all DDs }\end{array}$ & $\begin{array}{l}\text { Non-advocates } \\
\text { Advocates }\end{array}$ & $\begin{array}{l}1.98(0.54) \\
2.21(0.63)\end{array}$ & 2.45 & 201 & .02 \\
\hline $\begin{array}{l}\text { Total number of topics } \\
\text { in academic courses }\end{array}$ & $\begin{array}{l}\text { Non-advocates } \\
\text { Advocates }\end{array}$ & $\begin{array}{l}5.62(3.56) \\
6.18(3.13)\end{array}$ & 0.99 & 201 & .32 \\
\hline $\begin{array}{l}\text { Total number of } \\
\text { workshops attended }\end{array}$ & $\begin{array}{l}\text { Non-advocates } \\
\text { Advocates }\end{array}$ & $\begin{array}{l}1.19(2.02) \\
2.46(2.75)\end{array}$ & 3.01 & 67.17 & .004 \\
\hline $\begin{array}{l}\text { Total impact of increase } \\
\text { in knowledge }\end{array}$ & $\begin{array}{l}\text { Non-advocates } \\
\text { Advocates }\end{array}$ & $\begin{array}{l}7.37(0.85) \\
7.38(0.90)\end{array}$ & 0.08 & 200 & .94 \\
\hline $\begin{array}{l}\text { Total challenges and } \\
\text { stressors faced }\end{array}$ & $\begin{array}{l}\text { Non-advocates } \\
\text { Advocates }\end{array}$ & $\begin{array}{l}6.27(2.68) \\
7.00(2.48)\end{array}$ & 1.69 & 201 & .09 \\
\hline $\begin{array}{l}\text { Total feelings of } \\
\text { competence }\end{array}$ & $\begin{array}{l}\text { Non-advocates } \\
\text { Advocates }\end{array}$ & $\begin{array}{l}4.83(1.28) \\
5.37(1.01)\end{array}$ & 2.78 & 199 & .006 \\
\hline $\begin{array}{l}\text { Mean score on self- } \\
\text { efficacy scale }\end{array}$ & $\begin{array}{l}\text { Non-advocates } \\
\text { Advocates }\end{array}$ & $\begin{array}{l}6.80(0.88) \\
6.89(0.98)\end{array}$ & 0.58 & 201 & .56 \\
\hline
\end{tabular}

Self-efficacy. Correlations between sense of self-efficacy and 12 aspects of demographic and descriptive data about the teacher candidates appear in Table 5. Of these, two were significant, gender $(p=.01)$ and total feelings of competence $(p<.001)$. Men reported higher self-efficacy than women; however, only $12 \%$ of the participants were men. Higher reported competence was related to higher reported self-efficacy.

A multiple linear regression was conducted to determine whether gender and total feelings of competence predicted sense of self-efficacy. The overall model was significant, $F(2,202)=15.87, p<.001, R^{2}=.14$. Total feelings of competence (for teaching students with DD and for collaborating) was a significant predictor of teacher candidates' general sense of self-efficacy for teaching, $t=4.90, p<.001, \beta=.33$. In contrast, gender was not a significant predictor of sense of self-efficacy, $t=1.67, p=.10$, $\beta=-.11$. 
Table 5

Correlations with Teachers' Sense of Self-Efficacy Scale

\begin{tabular}{lc}
\hline Measure & $\boldsymbol{R}$ \\
\hline Gender & $-.172^{*}$ \\
Age & -.080 \\
Mean experience with DD (all ages) & .125 \\
Total types of DD in last practicum & .050 \\
Mean knowledge score across all DDs & .102 \\
Total number of topics in academic courses & -.052 \\
Total number of workshops attended & .044 \\
Total training in courses and workshops & -.017 \\
Total impact of increase in knowledge & -.062 \\
Total challenges and stressors faced & -.024 \\
Total feelings of competence & $.352^{* *}$ \\
Participation in advocacy or an organization $(\mathrm{Y} / \mathrm{N})$ & .041 \\
\hline${ }^{*} p<.05,{ }^{* *} p<.001$ &
\end{tabular}

Perceptions of challenges, stressors, and successes. Candidates reported their perceptions of the successes (Table 6) and challenges (Table 7) their schools were experiencing when including students with DD; they also reported their perceptions of the stressors they had experienced as pre-service teachers, when including students with DD in their classrooms (Table 8). The most frequently reported successes schools were experiencing included interaction between students with DD and their classmates; increased compassion in typical children; and increased acceptance, compassion, and awareness in staff. The greatest challenges to schools were difficulty managing behaviour, lack of funds to implement programs, and difficulty increasing interaction between children. The most commonly reported stressors candidates experienced during practicum included the need to sustain an active learning environment for all students, working with a student with inappropriate behaviours, being accountable for all students' academic outcomes, and working with a student with poor attention span. 


\section{Table 6}

\section{Successes School is Experiencing by Including Students with Developmental Delays and Disabilities in the Classroom}

\begin{tabular}{lrr}
\hline Success & $\mathbf{N}(\%)$ \\
\hline Students with DD interact with typical students & $151(72.9)$ \\
Increased acceptance, compassion, awareness in typical children & $141 \quad(68.1)$ \\
Increased acceptance, compassion, awareness in staff $^{\text {Promotes collaboration and partnership with parents }}$ & $127 \quad(61.4)$ \\
None of the above successes $_{\text {Other successes }^{\text {a }}}$ & $97 \quad(46.9)$ \\
\hline
\end{tabular}

Note. Categories are not mutually exclusive. $N=207$.

${ }^{a}$ Other successes included working with an EA $(n=1)$ and the ease of inclusion because there were few students with DD $(n=1)$.

Table 7

\section{Challenges School is Experiencing by Including Students with} Developmental Delays and Disabilities in the Classroom

\begin{tabular}{|c|c|c|}
\hline Challenge & & $(\%)$ \\
\hline Difficulty managing behaviour & 122 & $(58.7)$ \\
\hline Lack of funds to implement programs & 114 & $(54.8)$ \\
\hline Difficulty increasing interaction between children & 98 & $(47.1)$ \\
\hline Difficulty implementing an IEP & 90 & $(43.3)$ \\
\hline Lack of funds for inservice training & 90 & $(43.3)$ \\
\hline Lack of resource materials and intervention tools & 83 & $(39.9)$ \\
\hline Lack of support from staff members (e.g., resource teachers) & 37 & $(17.8)$ \\
\hline Negative staff attitudes & 34 & $(16.3)$ \\
\hline Other $^{a}$ & 10 & $(4.8)$ \\
\hline None of the above & 8 & (3.8) \\
\hline
\end{tabular}

Note. Categories are not mutually exclusive.

a Other challenges included academic challenges of accommodating all students $(n=4)$, identifying disabilities $(n=2)$, need for additional educational assistants $(n=3)$, and the absence of a forum for collaboration among teachers $(n=1)$. 
Table 8

Stressors Teacher Candidates Experience Working in Inclusive Setting

\begin{tabular}{lrc}
\hline Stressor & \multicolumn{2}{c}{$\boldsymbol{N}$ (\%) } \\
\hline Need to sustain active learning environment for all students & 127 & $(61.1)$ \\
Working with student who has inappropriate social behaviours & 114 & $(54.8)$ \\
Being accountable for all students' educational outcomes & 108 & $(51.9)$ \\
Working with student who has poor attention span & 106 & $(51.0)$ \\
Developing IEP or behavioural support plan for student with DD & 90 & $(43.3)$ \\
Obtaining funding to meet needs of student with DD & 71 & $(34.1)$ \\
Perceived lack of parental understanding of their child's capacities & 65 & $(31.3)$ \\
Other a & 6 & $(2.9)$ \\
None of the above & 8 & $(3.8)$ \\
\hline
\end{tabular}

Note. Categories are not mutually exclusive.

${ }^{a}$ Other stressors include balancing competing student needs $(n=2)$, lack of funding for educational assistants $(n=2)$, lack of early identification of needs $(n=1)$, disruptions in the classroom $(n=1)$.

\section{Themes in Qualitative Data}

Two open-ended questions asked teacher candidates to give "one example of a situation in which you felt particularly successful in meeting the needs of a child with a developmental delay and/or disability" and "one example of a situation in which you faced particular challenges in meeting the needs of a child with a developmental delay and/or disability." Following each question they were asked how their actions helped to promote the social inclusion of this child. Social inclusion was described as "a complex concept referring not only to a place, but also to a process whereby students with developmental delays and disabilities have opportunities to participate with non-disabled peers in social, recreational and educational settings." Standard methods of constant comparison (Patton, 2002) were used to conduct open coding on the written responses to generate codes that, when clustered, yielded three themes for successes and four themes for challenges.

Successes. Of 208 respondents, $177(85 \%)$ wrote responses to this open-ended question describing specific experiences of success, which were grouped into three themes: differentiating teaching and assessment; enhancing students' social, communication, and behavioural participation; and working with other adults.

Differentiating teaching and assessment. The predominant theme in the successes described occasions on which teacher candidates had differentiated teaching or assessment. They described many creative means they had used to enable students with DD to participate in a differentiated learning activity or assessment task. There were examples of developing alternative outcomes and of teaching toward these goals, including life skills, which were not on the school curriculum but were appropriate for individual students with DD, as well as examples of providing physical assistance and adaptive technology. 
Examples of differentiating instruction included teaching "in smaller chunks," providing "modified versions of the handouts," and "tweaking the steps" in a dance so a student with cerebral palsy could participate. One candidate provided a detailed description of using "a puppet who would help [one student with DD in a Kindergarten class] to color or write his letters." Another candidate described how she "asked students to do actions to show which instruments were playing" during a music lesson and "for the first time a student with autism participated actively." Many provided examples of "working one-on-one" with students, of "using hands-on lessons," "manipulatives," and "simplified language." Candidates described "modeling" tasks, "lots of positive reinforcement," and carefully selected partners for activities.

The means of differentiating assessment included using "modified assignments," giving individual oral assessments and shorter assessments "with less content and larger print," and "scribing" for students with DD. One candidate wrote that when an oral assessment was used, it was "clear that this child could learn and [could] demonstrate their learning if given the appropriate opportunity."

Teacher candidates provided many examples of giving students physical assistance and of using adaptive technology like "an amplification system." Others used a SMART board and "computer software" so students could listen to instructions rather than read them and could produce written answers. Some descriptions were elaborate: "A 13-year old had severe physical and developmental difficulties. With her limited range of movement, she was able to correctly identify objects presented to her on the screen with the use of specialized equipment." Teacher candidates described setting alternative outcomes that were not within the school curriculum and teaching students with DD to meet these outcomes. Examples included "toilet training girl with Down syndrome," and working with a speech pathologist to "facilitate group activities for children who stutter."

When asked how these successes promoted social inclusion, the candidates emphasized how students with DD were learning through tasks similar to those of their classmates (e.g., "same lessons" or "completing the same activity but at a more basic level") and were showing what they had learned on assessments that were appropriate to how they had been taught and that accommodated their needs. Students with DD were now "a part of the class and "made more contributions"; "the students liked working together and began to play at recess." One candidate reported that a young boy felt a "sense of belonging when he did the same work as peers [and had] a more positive attitude towards learning."

Enhancing social, communication, and behaviour participation. A second theme in the candidates' open responses focused on how they had changed the way they taught so children with DD enjoyed greater social participation in the life of the classroom and communicated more. They described using classroom management techniques to increase the appropriate behaviour of these students.

There were descriptions of encouraging a child with DD to "seek friends to play with during recess [and] prior to recess time... as a result he developed true friendships," many accounts of helping children with autism to "feel comfortable enough to join the group," and a specific example of making "an alphabet book about the students in the class" in 
which "everyone participated." Communication strategies used with children with autism included "talking one-on-one" to ensure they understood and introducing visual schedules. One candidate said she was "able to connect with a student [with autism] by finding a mode of similar communication - a calculator." Classroom management techniques included discerning "who he worked best with and that he needed to take breaks" and "using a token economy." One candidate wrote: "When working with a student who had difficulties with anger management, I carefully worded my questions when addressing the student so as not to set off his temper."

The candidates described the social and personal benefits for children with DD, referring to how these children participated more in class, "interacted" and "played more with peers," grew in confidence and other positive feelings, and were more "accepted by peers." One wrote: "My actions helped the other students to see how we can help other members of our society as I modeled through my actions."

Working with other adults. The third theme emphasized the candidates' successful experiences working with other adults for the benefit of children with DD, in contrast to the first two themes, which emphasized working directly with the children. The candidates described collaborating with their supervising teacher and other professionals, as well as advocating with other adults on behalf of students with DD. Examples of collaboration included candidates' describing how they built on what the classroom teacher had done (e.g., "student with FAS was already active and accepted member") and "communicated with parents successfully." Another reported that "through consultation with special education teacher and my associate teacher, [together] we were able to identify strategies to help him learn." The number of examples of advocacy by teacher candidates was surprising given the three-week length of each of their practica in classrooms. Examples included: "pointed out the strengths of a child who had autism, which allowed him to get involved with other children with the same interest," and implemented "a behavioral strategy for a child with ASD [autism spectrum disorder] that helped change parents' attitude toward the child's capacity." One candidate wrote about collaborating with other teachers in her school:

I was able to help facilitate a simulation day so students in my Grade 2 class could experience the low vision and very low hearing that one of my students lives with daily. The students really got it and had a better understanding for why that student sometimes received extra attention.

Candidates described the effects of these kinds of actions as "reintegrating the child into the daily functions of the classroom," and as helping other students "to further understand him as an individual."

Challenges. Of the 208 participants, 163 (78\%) provided qualitative data on challenges. Four themes emerged from the analysis: dealing with disruptive behaviour, differentiating teaching, negotiating differences in adult perspectives, and being a preservice teacher.

Dealing with disruptive behaviour. One of the most prominent challenges was dealing with disruptive behaviour. While off-task and defiant behaviour were mentioned, the teacher candidates reported most difficulty with emotional or behavioural outbursts. When students exhibited agitated or emotional behaviour, respondents found it 
challenging to "calm them down." One candidate described being "in a placement with a severely autistic child and [I] didn't know how to react." Another wrote that a "student would yell and run out of the room when I tried to talk to her." Other challenges included "outbreaks of frustration, screaming, crying" and children "out of control."

When asked how these challenges limited social inclusion, the teacher candidates reported that they thought these externalized displays led to exclusion by peers who were "uneasy being around the student after the outbreaks" and who were "afraid of him." The teacher candidates were unsure how to facilitate peer inclusion in these conditions and one said "the children didn't know how to relate either."

Differentiating teaching, especially modified curriculum expectations. The second theme focused on the challenges of differentiating teaching, a theme that also appeared in the candidates' successes. This reflects the dilemmas inherent in inclusive education of children with DD. The candidates were challenged to include students with a "range of abilities," especially when students were working toward modified curriculum expectations that were well below the grade level of the class. "I feel challenged when I feel they want to be part of the class but I can't give them the same work academically because they aren't ready. I feel challenged to provide different levels of work to different students." Another candidate described "difficulty meeting needs because there were so many modifications in so many subjects," and another observed that "we never took the time to come up with challenging work for special needs students."

The candidates felt that the challenge of differentiating teaching limited social inclusion for a number of reasons. Sometimes it meant students with DD were "[taught] out of the classroom" or "at the back table" and "the child was often doing different work than the other students and probably felt less engaged than he could have been" or felt "excluded from other children his age" because he was completing different activities.

Differences in adult perspectives. The third challenge described by teacher candidates focused on the dilemmas that arise when the adults around a child with DD have different perspectives. These differences in perspective can arise between the candidate and the host teacher and between the teachers and the parents. One teacher candidate wrote, "Since I am only the TC, it isn't possible [for me] to change much about classroom, set-up, rules, or routines which I felt might have helped all the students learn more successfully," and another was frustrated because "I wasn't told [by my host teacher] which students had an IEP. Therefore my lessons were not differentiated for these students." In commenting on their differences with parents, teacher candidates wrote that a "parent refused to allow assessment/identification," which the candidate believed may have led to "difficulty modifying/accommodating, especially for assessment"; and "guardians would not provide him with medication" and, in the candidate's view, "with the medication he had [previously] been able to learn successfully."

Teacher candidates saw the challenges arising from different perspectives as limiting inclusion because they felt they were not able to meet the needs of their students while working under these constraints. Without an IEP and changes in teaching, the student 
"did not participate and therefore did not learn" and, without medication, another student "lacked motivation and became disruptive in class."

Being a pre-service teacher. Not surprisingly, some teacher candidates expressed frustration about their own limitations as pre-service teachers. They found it challenging to be knowledgeable about a wide range of disabilities, to understand how the school system works, and to respond flexibly to changes in classroom routine. One wrote, "I just don't feel adequate in meeting the needs of children with a disability or developmental delay"; and another said, "When you don't know much about a developmental delay, it is frustrating to find help right away. So much red tape just to get help for one student." Another teacher candidate wrote, "A child with Down syndrome-I did not understand how to help when the resource teacher left. I could play with him but I was lost on how to help him academically."

A few candidates expressed how their own limitations were compounded by the general lack of human resources. One reported on "a classroom with three severely autistic children and only one educational assistant. It was hard to meet the needs without adequate support," and another candidate described a "child [who] never stays in class, wanders, and won't participate. There is no help with her." Respondents thought that these challenges limited social inclusion because they made it very difficult for the teacher candidates to meet the students' needs "while learning to teach."

\section{Discussion}

\section{Using Mixed Methods}

Mixed-methods studies provide rich opportunities to compare perspectives expressed in quantitative and qualitative data on the same topics. For example, in the current study, teacher candidates were asked: to choose from a list all the challenges they thought their school was experiencing when including children with DD; to choose from a list of stressors the ones they were experiencing working in an inclusive setting; and to write a brief response to an open-ended question about a challenge they had faced in meeting the needs of a child with DD. The five most selected challenges from the list included two social challenges (difficulty managing behaviour and difficulty increasing interaction between children), one academic challenge (difficulty implementing an IEP), and two funding challenges (lack of funds to implement programs and lack of funds for in-service training). The top four personally experienced stressors included two focused on academic challenges in teaching (sustaining an active learning environment for all students and being accountable for all students' educational outcomes) and two more behaviourally oriented challenges (working with students with inappropriate social behaviours and with students with poor attention span). So while the candidates recognized financial challenges in schools (consistent with the findings of Subban \& Sharma, 2005), the personal stressors they chose were the classic challenges of teachers with diverse classes - meeting the academic and behavioural needs of all their students (e.g., Stanovich, 1999). In comparison, the four themes that emerged from the analysis of qualitative data on challenges were: dealing with disruptive behaviour, differentiating teaching, differences in adult perspectives, and being a pre-service teacher-the classic 
behaviour and academic challenges plus two challenges not usually sought in questionnaire research. These pre-service teacher candidates reported that there are unique challenges in inclusive classrooms associated with being a pre-service teacher candidate that teacher educators must consider-adults do not always agree on the best outcomes or means of reaching these outcomes for students with DD. And the final theme suggests that the stressful, novice, and relatively powerless role of pre-service teachers places them in a difficult position when adults do not agree. Their unique perspective as teacher candidates emerges when we listen, even if the qualitative data are only a paragraph in response to an open-ended question on a questionnaire.

\section{Including a Focus on Successes}

Similar comparisons of quantitative and qualitative data sources can be made for the data on successes. From the list of four choices, all of which were social in nature, teacher candidates focused on the interactions involving children with DD and their peers (students with DD interact with typical students and increased acceptance by typical children). However, when the candidates could focus on what they had personally experienced, the three themes that emerged from the analysis of the qualitative data were not all social in nature-differentiating teaching and assessment, enhancing participation (behavioural, social, and communication), and working with other adults (parents and teachers). The teacher candidates were clear that these successes, which may not all appear to be social in nature, contributed to social inclusion. These data show the teacher candidates' understanding of the critical role of differentiated instruction in educational and social inclusion in the classroom (Hutchinson, 2014). More importantly, the data on successes show clearly that when you ask about success, teacher candidates will report on their accomplishments in inclusive classrooms (Preskill \& Catsambas, 2006), just as experienced teachers did when asked about their successes in Stanovich's (1999) focus group, which was also conducted with Ontario educators. These findings suggest that if we wish to understand the perspectives of pre-service teachers on inclusion of children with DD and other disabilities, we may need to extend the range of items on quantitative measures and supplement these with rich qualitative data.

\section{Dilemmas Inherent in Inclusive Education}

It is also noteworthy that the teacher candidates appear to understand the dilemmas associated with inclusive education: Some of the challenges they reported in their qualitative data were reported in the qualitative data on successes as well. For example, differentiating teaching and assessment was the predominant theme in the successes and was the second theme in the challenges. On the other hand, the predominant challenge they reported was dealing with disruptive behaviour, while enhancing various forms of social participation was the second theme in successes. Working with other adults was also represented as a challenge and as a success, and the unique role of the pre-service candidate was recognized as contributing to this challenge. Thus the candidates could recognize, at the same time, all they had accomplished in these aspects of inclusive education, while still acknowledging how much they needed to learn and the dilemmas that make inclusive education so complex (Hutchinson, 2005). Although the candidates 
did not include words like ethical decision making in their brief written responses to the open-ended questions, they showed a sophisticated awareness that inclusive teaching is a moral and collaborative endeavor, and involves much more than technical expertise.

\section{Collaboration, Experience, and Knowledge}

Collaboration with teachers, professionals, and parents was prominent in the perspectives of the teacher candidates in this study, as has been found in previous research (Arthaud et al., 2007; Villeneuve \& Hutchinson, 2012). They found colleagues to be their best and most used resource in schools, felt competent to collaborate, and focused on working with other adults when reporting their successes and their challenges. Teacher candidates' feelings of competence to collaborate and to teach students with DD, taken together, were the best predictor of general self-efficacy for teaching. This suggests that, in primary-junior classrooms (Kindergarten to Grade 6), inclusion of students with DD is part of the general experience of teaching and that those who feel confident to teach also feel confident to include students with disabilities (Ajuwon et al., 2012). These data are consistent with the finding of Montgomery and Mirenda (2014) that, for practising teachers, self-efficacy for collaboration predicted more positive attitudes and fewer concerns about including students with DD. The current data also suggest that there are close connections among knowledge, experience with individuals of any age with disabilities, and feelings of competence for teaching students with DD and for collaboration. The data showed consistencies in the ordering of the specific forms of DD, with autism being the DD they knew most about and had most experience with, while the same three low-incidence DD were consistently ranked lowest for knowledge and experience (Fragile X, epilepsy, and Tourette syndrome). These findings suggest that it is important to include preparation to collaborate with other educators, other professionals, and parents in teacher education programs and to seek teacher candidates who have experience, knowledge, and confidence about teaching students with DD.

\section{Advocacy, Self-efficacy, and Further Learning}

In this study, approximately $25 \%$ of the participants reported advocacy experience, and these individuals reported greater knowledge and more relevant experience with individuals with DD than those without advocacy experience. Those reporting advocacy experience also reported greater feelings of competence, and feelings of competence was the only predictor of self-efficacy in this study (Ajuwon et al., 2012). Only about $25 \%$ of the respondents had attended a resource team meeting, while $85 \%$ had been introduced to IEPs or behavioural plans by their host teachers, suggesting that they might benefit from more education about the teacher's role in the resource team (Hutchinson, 2014; Villeneuve \& Hutchinson, 2012). The candidates expressed a desire for further education about the two major challenges they identified in the qualitative data (behaviour interventions and academic modifications), which is consistent with the finding that, while most candidates expressed feeling moderately or very competent to collaborate, only $37 \%$ reported that they felt moderately or very competent to meet the needs of children with DD. 


\section{Limitations and Future Research}

A number of limitations in this study must be acknowledged. First, the participants were from one university in the province of Ontario, thus limiting external validity. In Ontario the predominant model for teacher education has been an 8-month after-degree program. This institution uses personal statements of experience in combination with grades to select candidates. That might have resulted in the candidates in this sample having more relevant experience than those accepted into programs that do not use personal statements of experience for admission. Each year, in this institution, there are about 350 candidates preparing to teach in primary-junior classrooms, from Kindergarten to Grade 6; and of these, 208 completed questionnaires. Sections (with 30 to 40 students each) of a required course were selected randomly to receive questionnaires, but individual teacher candidates were not selected randomly. There was a small number of male respondents in this study, consistent with the low participation by males in the primary-junior teacher education program. As a result, analyses by gender need to be interpreted very cautiously. Additional studies are needed to judge the extent to which these findings apply to teacher candidates in other programs. Unlike many previous studies of teacher candidates, we chose to administer the surveys at the mid-point of the program to learn about the teacher candidates' perspectives while they were still in the program and still expected to complete practica in inclusive classrooms. We judged this a better way to learn their views than to wait until after all practica had been completed, when there were no immediate demands on the candidates to engage in inclusive teaching with students with DD. However, it is possible that our results were influenced by the timing of the administration of the survey.

While the instrument provided examples of what was meant by DD, a small number of candidates' responses to the open-ended questions included comments about students with attention deficit hyperactivity disorder, which suggested these individuals were thinking about a wide range of disabilities including some that would not normally be considered DD. However, the majority of references to specific disabilities in the openended data were to autism, followed by developmental disabilities and Down syndrome. The instrument included a definition of social inclusion that emphasized students with DD having opportunities to participate with non-disabled peers in educational and other social contexts. Future studies might benefit from using an instrument that has undergone more extensive development and revision such as the SACIE-R (Forlin et al., 2011) and from using interviews to clarify the meaning respondents hold for terms like developmental disabilities and delays or social inclusion.

In Ontario, teachers are encouraged to complete a series of three additional qualification (AQ) courses in special education or inclusive education, which appear on their official record of teaching qualifications (Killoran et al., 2013). These courses are available at universities and district school board offices across Ontario and as online courses. The number of respondents who enrolled in these courses following completion of the post-degree program was not researched for inclusion in this study. Future research should examine the relationship between candidates' perspectives on inclusion of students with DD and the likelihood of their enrolling in AQ courses after graduation. Because Ontario has adopted a model of inclusive, full-day Kindergarten, in which a primary-junior teacher and an early childhood educator will collaborate in each 
Kindergarten classroom (Ontario Ministry of Education, 2011), it would be beneficial to investigate similarities and differences in the perspectives of these two groups of educators on inclusion of children with DD. Lastly, this mixed-methods study suggests that qualitative items elicited more optimism (Stansberry Beard et al., 2010) than traditional survey items, even when positively worded survey items accompanied implicitly negatively worded items. As well as typical survey items, which tend to elicit the challenges associated with inclusive education, future studies should include both positively worded survey items and open-ended items or interview questions to enable a broader range of responses, and to ensure opportunities for teacher candidates to express their perspectives deeply, even acknowledging the dilemmas inherent in inclusive practice.

\section{Implications}

The results highlight the relationship of general self-efficacy for teaching to reported sense of competence to collaborate with colleagues and to teach students with DD. In addition, qualitative items about collaboration offered a window into the views of teacher candidates on strategies that they see as particularly valuable at the beginning of their careers. These findings suggest that teacher educators need to tap the optimism of teacher candidates. By teaching them to collaborate, we may strengthen their ability to use collaboration, which they already value, to enhance the inclusion of students with DD while meeting the needs of all their students. As well, the results suggest that experience in organizations that advocate for individuals with disabilities may be related to having knowledge and confidence to include students with DD. Teacher candidates may also be more aware of the dilemmas inherent in inclusive education than previous research has suggested; building on this awareness may enable teacher educators to better prepare candidates for the complex realities of inclusive classrooms where they must work with other adults, who often hold different views and values. Finally, given that research has demonstrated that teachers with positive attitudes toward inclusion are more likely to meet the needs of students with DD and other disabilities, and given that experience, knowledge, and competence appear to be closely related, teacher education programs should ensure that pre-service candidates have positive opportunities to learn about and work with children with disabilities.

\section{References}

Ajuwon, P. M., Lechtenberger, D., Griffin-Shirley, N., Sokolosky, S., Zhou, L., \& Mullins, F.E. (2012). General education pre-service teachers' perceptions of including students with disabilities in their classrooms. International Journal of Special Education, 27(3), 100107.

Arthaud, T. J., Aram, R. J., Breck, S. E., Doelling, J. E., \& Bushrow, K. M. (2007). Developing collaboration skills in pre-service teachers: A partnership between general and special education. Teacher Education and Special Education, 30, 1-12.

Avramidis, E., Bayliss, P., \& Burden, R. (2000). Student teachers' attitudes towards the inclusion of children with special educational needs in the ordinary school. Teaching and Teacher Education, 16, 277-293. 
Brady, K., \& Woolfson, L. (2008). What teacher factors influence their attributions for children's difficulties in learning? British Journal of Educational Psychology, 78, 527-544.

Clegg, J., Murphy, E., Almack, K., \& Harvey, A. (2008). Tensions around inclusion: Reframing the moral horizon. Journal of Applied Research in Intellectual Disabilities, 21, 81-94.

Daniel, K. (2011). Identifying the gap towards an inclusion education system within Québec: Collectively examining the perceptions of different groups of educators. (Doctoral thesis, McGill University, Montréal, Canada).

Daniel, K., \& Cornish, K. (2006). The McGill Inclusive Education Questionnaire. Unpublished manuscript. Montreal, QC: McGill University.

Forlin, C., Earle, C., Loreman, T., \& Sharma, U. (2011). The Sentiments, Attitudes, and Concerns about Inclusive Education Revised (SACIE-R) Scale for measuring pre-service teachers' perceptions about inclusion. Exceptionality Education International, 21(3), 50-65.

Forlin, C., Loreman, T., Sharma, U., \& Earle, C. (2009). Demographic differences in changing preservice teachers' attitudes, sentiments and concerns about inclusive education. International Journal of Inclusive Education, 13, 195-209.

Hutchinson, N. L. (2005). Critical reflection by teacher candidates on cases based in their experience: Teacher education for inclusive education. Exceptionality Education Canada, 14(2-3), 89113.

Hutchinson, N. L. (2014). Inclusion of exceptional learners in Canadian schools: A practical handbook for teachers (4th ed.). Toronto, ON: Prentice Hall.

Jordan, A., Glenn, C., \& McGhie-Richmond, D. (2010). The Supporting Effective Teaching (SET) project: The relationship of inclusive teaching practices to teachers' beliefs about disability and ability, and about their roles as teachers. Teaching and Teacher Education, 26, 259266.

Killoran, I., Zaretsky, H., Jordan, A., Smith, D., Allard, C., \& Moloney, J. (2013). Supporting teachers to work with children with exceptionalities. Canadian Journal of Education, 36(1), 240-270.

Montgomery, A., \& Mirenda, P. (2014). Teachers' self-efficacy, sentiments, attitudes and concerns about the inclusion of students with developmental disabilities. Exceptionality Education International, 24(1), 18-32.

Nachshen, J., Anderson, L., \& Jamieson, J. (2001). The Parent Advocacy Scale: Measuring advocacy in parents of children with special needs. Journal on Developmental Disabilities, 8, 93-105.

Ontario Ministry of Education. (2011). Full day Kindergarten: Who is working in the classroom? Retrieved from: http//www.edu.gov.on.ca/kindergarten/

Patton, M. Q. (2002). Qualitative research \& evaluation methods (3rd ed.). Thousand Oaks, CA: Sage.

Preskill, H. S., \& Catsambas, T. T. (2006). Reframing evaluation through appreciative inquiry. Thousand Oaks, CA: Sage.

Robinson, J. P., Shaver, P. R., \& Wrightsman, L. S. (1991). Criteria for scale selection and evaluation. In P. Robinson, P. R. Shaver, \& L. S. Wrightsman (Eds.), Measures of personality and social psychological attitudes (pp. 1-16). San Diego, CA: Academic Press.

Sari, H., Celikoz, N., \& Secer, Z. (2009). An analysis of pre-school teachers' and student teachers' attitudes to inclusion and their self-efficacy. International Journal of Special Education, 24, $29-44$. 
Sokal, L., \& Sharma, U. (2014). Canadian in-service teachers' concerns, efficacy, and attitudes about inclusive teaching. Exceptionality Education International, 23, 59-71. Retrieved from http://ir.lib.uwo.ca/eei/vol23/iss1/5

Stanovich, P. J. (1999). Conversations about inclusion. Teaching Exceptional Children, 31(6), 54-58.

Stansberry Beard, K., Hoy, W. K., \& Woolfolk Hoy, A. (2010). Academic optimism of individual teachers: Confirming a new construct. Teaching and Teacher Education, 26, 1136-1144.

Subban, P., \& Sharma, U. (2005). Understanding educators' attitudes toward implementation of inclusive education. Disability Studies Quarterly, 25, no. 2. Retrieved from http://dsqsds.org/article/view/545/722.

Swain, K. D., Nordess, P. D., \& Leader-Janssen, E. M. (2012). Changes in preservice teacher attitudes toward inclusion. Preventing School Failure, 56(2), 75-81.

Symeonidou, S., \& Phtiaka, H. (2009). Using teacher' prior knowledge, attitudes, and beliefs to develop in-service teacher education courses for inclusion. Teaching and Teacher Education, $25,543-550$.

Tourangeau, R., Rips, L. J., \& Rasinski, K. (2000). The psychology of survey response. Cambridge, UK: Cambridge University Press.

Tschannen-Moran, M., \& Woolfolk Hoy, A. (2001). Teacher efficacy: Capturing an elusive construct. Teaching and Teacher Education, 17, 783-805.

Villeneuve, M., \& Hutchinson, N. L. (2012). Enabling outcomes for students with developmental disabilities through collaborative consultation. Qualitative Report, 17(Art. 97), 1-29. Retrieved from http://www.nova.edu/ssss/QR/

Wishart, J. G., \& Manning, G. (1996). Trainee teachers' attitudes to inclusive education for children with Down's syndrome. Journal of Intellectual Disability Research, 40, 56-65.

\section{Authors' Note}

Correspondence concerning this article should be addressed to Nancy Hutchinson, Faculty of Education, Duncan McArthur Hall, 511 Union Street, Queen's University, Kingston, ON, K7M 5R7, Canada. Email: hutchinn@queensu.ca 